\title{
İnovasyon Kültürü ve İnovasyon Kültürünün Boyutlarının Belirlenmesi Üzerine Keşifsel Bir Araştırma
}

\author{
Merve Melek SARIGÜL ${ }^{1}$ (iD) Ahmet ÇUBUKÇU ${ }^{2}$ iD
}

\begin{abstract}
${ }^{1}$ Yüksek Lisans Öğrencisi, Necmettin Erbakan Üniversitesi, Uygulamalı Bilimler Fakültesi, Yönetim Bilişim Sistemleri, Konya, Türkiye mervemeleksarigul@gmail.com (Sorumlu Yazar/Corresponding Author)

${ }^{2}$ Doktor Öğretim Üyesi, Necmettin Erbakan Üniversitesi, Mühendislik ve Mimarlık Fakültesi, Adli Bilişim Mühendisliği, Konya, Türkiye

acubukcu@erbakan.edu.tr
\end{abstract}

\begin{tabular}{|c|c|}
\hline Makale Bilgileri & ÖZ \\
\hline $\begin{array}{l}\text { Makale Geçmişi } \\
\text { Geliş: } 06.08 .2020 \\
\text { Kabul: } 22.02 .2021 \\
\text { Yayın: } 30.06 .2021\end{array}$ & $\begin{array}{l}\text { Yenilik faaliyetleri toplumları yapısal, sosyal ve çevresel açıdan etkilemektedir. Bu yenilik } \\
\text { faaliyetlerinin ortaya çıkması toplumun kültür özellikleri ile de yakından ilgilidir. O yüzden kültür, } \\
\text { toplumda yaşayan insanların değerlerini, yaşam biçimlerini, düşüncelerini ortaya koyan ve } \\
\text { şekillendiren tarihsel bir süreçtir. Bu süreç kurumların yeniliği özümsemeleri için örgüt kültürünün } \\
\text { oluşumunu sağlamaktadır. Örgüt kültürü, inovasyon külttürü ile ilişkili en önemli faktörlerden biridir. }\end{array}$ \\
\hline $\begin{array}{l}\text { Anahtar Kelimeler: } \\
\text { Külttür, Örgüt Kültürü, } \\
\text { İnovasyon Kültürü, }\end{array}$ & $\begin{array}{l}\text { Bu çalışmada inovasyon ve örgüt kültürünün boyutları üzerine yapılan çalışmalar incelenerek } \\
\text { kavramsal çerçeveye en uygun inovasyon kültürü modeli belirlenmeye ve bu kapsamda gelecek } \\
\text { çalışmalara yön verilmeye çalışılmıştır. }\end{array}$ \\
\hline
\end{tabular}
İnovasyon Kültür Modeli.

JEL Kodlari: M14,

O30, 031

\section{Innovation Culture Models and A Research on Analysis of These Models}

\begin{tabular}{ll}
\hline Article Info & ABSTRACT \\
\hline Article History & $\begin{array}{l}\text { Innovation activities affect societies structurally, socially and environmentally. The emergence of } \\
\text { these innovations for the sustainable competition of societies is closely related to the cultural } \\
\text { characteristics of that society. Therefore, culture is a historical process that reveals and shapes the }\end{array}$ \\
$\begin{array}{l}\text { Received: } 06.08 .2020 \\
\text { Accepted: } 22.02 .2021\end{array}$ & $\begin{array}{l}\text { values, lifestyles and thoughts of the people living in the society. This process reveals the formation } \\
\text { of an organizational culture for institutions to absorb innovation. Organizational culture is one of the } \\
\text { most important factors associated with innovation culture. In this study, the studies on innovation }\end{array}$ \\
$\begin{array}{l}\text { Keywords: } \\
\text { and organizational culture dimensions are examined and the most appropriate model for the } \\
\text { Organization Culture, }\end{array}$ & $\begin{array}{l}\text { conceptual framework is determined and it is tried to make a direction for future studies in this } \\
\text { context. }\end{array}$
\end{tabular}

Innovation $\mathrm{C}$

Model.

Jel Codes: M14, O30,

031

Atıf/Citation: Sarıgül, M. M. ve Çubukçu, A. (2021). İnovasyon Kültürü ve İnovasyon Kültürünün Boyutlarının Belirlenmesi Üzerine Keşifsel Bir Araştırma, Necmettin Erbakan Üniversitesi Siyasal Bilgiler Fakültesi Dergisi, 3(1), 1-16.

"This article is licensed under a Creative Commons Attribution-NonCommercial 4.0 International License (CC BY-NC 4.0)" 


\section{GİRIŞ}

Değişen rekabet çerçevesinde, günümüz kurumları yenileşmeyi bir araç olarak görmektedir. Organizasyonların ve örgütlerin bu yenileşme sürecinde kendi içlerinde farklılaşmaları kaçınılmaz olmaktadır. Bu oluşan farklılıkları en aza indirgemek ve örgütlerin devamlılığını sağlamak için yeni arayışlar başlamıştır. İşte bu arayışları çağımızda inovasyon kavramı karşılamaktadır.

İnovasyon, işgücü, bilgi ve altyapı öğelerinin bilgiye, ürünlere, hizmetlere ve sistemlere yeni bir yaklaşım ile uyarlanması halidir. $\mathrm{Bu}$ yönden inovasyon, yenileşmeye açık olan, değişim sürecine uyumlu ve girişimcilik kavramıyla bütünleşen bir kültür ürünüdür (Yılmaz \& İncekaş, 2018, s. 155). İnovasyon olgusunun kültürle nasıl entegre edileceğinin karmaşıklığı ve kültürel bakış açısının inovasyonu anlamak ve uygulamak için oldukça elzem olması inovasyon kültürünü daha da önemli hale getirmektedir (Ismail \& Abdmajid, 2007, s. 41). İnovasyon yapılacaksa bunun oturmuş bir inovasyon kültürü ile başarılabileceği açık hale gelmiştir. Organizasyonlar inovasyon için fırsatları belirleyip bu konuda gelecek vaat eden bilgiye odaklanırsa, inovasyon odaklı örgüt kültürünü teşvik edebilir ve kendini yenilemede başarıyı yakalayabilir (Engel, 2018, s. 255). Bu nedenle örgütlerde inovasyon kültürü, inovasyonun oluşmasındaki ön koşullardan biridir. Literatürde inovasyon kültürünün oluşumu ile örgüt kültürünün boyutları arasında bir ilişkili olduğu görülmektedir. Bu yüzden bir kurumda inovasyon kültürünün oluşması için örgütün temel özellikleri belirlenmelidir. Bu özellikler ışığın da her örgüt kendi değer ve yargılarına uygun olarak inovasyon kültürünü oluşturmaktadır.

Bu çalışmada, inovasyon kültürü olgusunun anlaşılmasına, yaygınlaştırılmasına önemli düzeyde katkıda bulunmuş olan bilimsel çalışmalar, kavramsal bir çerçeve oluşturabilmek amacıyla araştırılmış ve incelenmiştir. Bu kapsamda literatürde kabul görmüş modeller incelenerek gelecekteki çalışmalara kaynak oluşturması açısından en uygun inovasyon kültürü modeli çalışılmıştır.

Çalışmanın ilk kısmında kültür kavramına yer verilmiştir. Kültür kavramının örgüt kültürüyle bağlantısı kurularak örgüt kültürü tanımı yapılmış ve örgüt kültürü boyutlarına değinilmiştir. Daha sonra kavramsal çerçeve 1şığında örgüt kültürü ve inovasyon kültürü arasındaki ilişki incelenerek inovasyon kültürü kavramı tanımlanmıştır. Daha sonra inovasyon kültürünün boyutları ve bu kapsamda ortaya konan modeller incelenmiştir. En uygun inovasyon kültürü modeli literatür taramasından elde edilen kavramsal çerçeve 1şığında ortaya konarak gelecekteki çalışmalar için bu modelin nasıl değerlendirilebileceği çalışmada analiz edilmiştir.

\section{Kültür}

Kültür insanları örgütsel, ulusal ve sosyal yönleriyle ilgilendiren bir yapıdır (Best, 2018, s. 66). Başka bir ifadeyle kültür, belirli bir bölgedeki kişilerin değer yapılarını, taşıdıkları özellikleri ve sergiledikleri davranışları kapsayan değerler bütünüdür. Bu değerler zaman içerisindeki etkilerini azaltarak yeni değerlerin oluşumuna olanak sağlamıştır. Bu nedenle kültür toplumun gereksinimlerine göre kademeli ve sürekli değişim içerisindedir (Yiğit, 2014, s. 2).

Toplumların çeşitliliği, kültür olgusunu her defasında etkileyerek toplumların algısını değiş̧irmiş ve her zaman daha yenilikçi sistemleri ortaya çıkarmıştır. Bu yüzden yenilik literatüründe kültürün tanımı biraz farklıdır. Ayrıca değerler genellikle kültürel özelliklerin bir katmanı olarak görülmektedir. Değerlerin buradaki en önemli etkisi yenilikçi bir ortam için kurum kültürünü temsil etmesidir.

\section{Örgüt Kültürü}

Örgüt kültürü birçok sentezi içerisinde barındırmaktadır. Psikoloji, sosyoloji, sosyal psikoloji, siyaset bilimi gibi alanlara konu olması örgüt kültürü kavramının alanını bir hayli genişletmiştir. $\mathrm{Bu}$ nedenle kurumlar örgüt kültürünün kendilerine ait olduğunu söylese de tanımlamalarda ortak noktalara 
da (örneğin müşteri odaklılık, memnuniyet, çalışanlara verilen değer, ödül vb.) değindikleri görülmektedir. $\mathrm{Bu}$ da örgüt kültürünün karmaşık bir yapısının olduğunu ve tanımlanmasının güç olduğunu göstermektedir (Yiğit, 2014, s. 3). Genel anlamda örgüt kültürü, örgütün varlığ1, vizyon ve misyon hakkında çalışanların arasında paylaşılan değerlerin ve inançların toplamı olarak ifade edilmektedir (Zanjirchi, Jalilian, \& Mehrjardi, 2019, s. 328). Bu nedenle örgütsel kültür, çalışanların izlemesi gereken yönetim ilkelerini oluşturan, bunların yürütülme şeklini ortaya koyan sistemlerin temellerini oluşturmaktadır (Tian, Deng, Zhang, \& Salmador, 2017, s. 9). Bu sistemler yeniliği incelemek için örgüt kültürünün alt boyutlarından faydalanarak kendi kültür değerlerini ortaya koymaktadir.

Literatürde örgüt kültürünün tanımı konusunda fikir birliği bulunmamakla birlikte, kültürün önemli bir yönünün, grupların belirli şeyleri ortak olarak paylaşması veya tutması konusunda daha geniş bir mutabakat vardır (Schein, 2004, s. 12). Bunlar genellikle bir kurumun veya alt birimlerinin temel varlığını oluşturan değerler, normlar, tutumlar ve davranış kalıpları olarak nitelendirilebilir (Herzog \& Leker, 2010, s. 324). Güçlü bir örgüt kültürü, çalışanların davranışlarını şekillendiren ve herkesin işletmenin hedeflerine ulaşmaya yönelik çalışmasını sağlayan ortak değerler, kurallar ve normlar sağlar (Olmos-Peñuela vd., 2017, s. 3).

Örgüt kültürüne ilişkin görüldüğü üzere pek çok sayıda tanımlama mevcut olmakla birlikte örgüt kültürü, bir işletmenin faaliyetlerini yürütme şeklini ortaya koyan bir dizi değer, inanç, varsayım ve sembolün bir yansıması olarak tanımlanabilmektedir.

\section{Örgüt Kültüründen İnovasyon Külttürüne}

İnovasyonu kolaylaştırmak için Büschgens vd. (2013, s. 2), işletmelerin inovasyon çabalarını tanıyan ve başarısızlığa tahammül eden güçlü ortak değerlere ve inançlara dayalı bir kültüre ihtiyaç duyduklarını iddia etmektedir. Bu kültür örgüt kültüründen inovasyon kültürüne giden bir yolu da aralamaktadır (Jin, Navare \& Lynch, 2019, s. 613).

Örgüt kültürü hem işletme meseleleri ile ilgili ortak anlayışın oluşmasını hem de örgüt üyelerinin ortak algılarını içerir. Örgüt kültürü ayrıca bireylerin belirli bir bağlamda kabul edilebilir ve kabul edilemez davranışlar arasında ayrım yapmalarına yardımcı olur ve kurumların bir sistem olarak başarısızlık, hatalar, başarı ve ödüller gibi bireysel performans meseleleri ile başa çıkılmasını yönetir. Ayrıca örgüt kültürü, bireylerin günlük eylemlerinde ve "hangi ölçüde risklerin kabul edilebilir olduğu", “ödül beklentileri” ve "etkin ekip çalışması" gibi karar alma süreçlerinde önemli bir rol oynar (Burdon, Kang \& Mooney, 2016, s. 76).

Örgüt kültürü aynı zamanda organizasyon tarafindan yürütülen yenilikçi faaliyetlerin çekirdeği olarak da ifade edilmektedir. İnovasyon kültürü, yeni fikirlerin formüle edildiği, değer verildiği ve desteklendiği bu kültür etrafında döner. Burada örgüt kültürü inovasyon kültürünü etkileyebilir ve bu kültür örgütlerin bazı bölümlerinde daha yaygın ya da daha nadir hale gelebilir. Örgüt kültürü, inovasyon kültürü aracılığıyla yaratıcılığı ve özgünlüğü teşvik edebileceğinden uygun bir şekilde birbirlerini besler (Abdul-Halim vd., 2018, s. 3).

Örgüt kültürü işbirlikçi faaliyetleri desteklediğinde ve bireyleri grup içi problem çözme konusunda iş birliği yapmaya teşvik ettiğinde, fikir üretimi süreci kolaylaştırır. Kültür yapısının iş birliği ve bilgi paylaşımına olanak sağlaması ve organizasyonda yeni fikirlerin ortaya çıkmasını engellemesi gerekir (Zanjirchi, Jalilian, \& Mehrjardi, 2019, s. 328). Fikir üretme ve olgunlaştırma süreci, inovasyon sürecinin önemli bir basamağı olduğu için kültür ve inovasyon arasında da kuvvetli bir bağ oluşmaktadır. 


\section{İnovasyon Külttürü}

Kurumsal kültür işletmelerin büyümesinde önemli bir faktör olmakla birlikte inovasyon kültürünün işletmelerin performası üzerinde doğrudan etkili olduğunu gösteren birçok çalışma mevcuttur (Tang vd., 2020, s.4). İnovasyon sürecinin tamamında kurumsal bir inovasyon kültürü varsa değişim ve yenileşim daha hızlı ve etkili olmaktadır (Yiğit, 2014, s. 6). İnovasyon kültürü, uyumu, sadakati ve bazı açık tutum kurallarını ve uygun davranışları güçlendirdiği için önemlidir. Bu nedenle inovasyon gibi inovasyon kültürü de çok yönlü bir yapıya sahip olduğundan dolayı genel kabul görmüş bir tanımı yoktur. Farklı yazarlar tarafından inovasyon kültürüne ilişkin yapılan tanımlamalar Tablo 1'de görülmektedir.

Tablo 1. Inovasyon Kültürü Tanımları

\begin{tabular}{|c|c|c|}
\hline Yazar & Yıl & Tanım \\
\hline Herzog \& Leker & 2010 & $\begin{array}{l}\text { Açık inovasyon ve kapalı inovasyona ilişkin inovasyon } \\
\text { kültürlerinin nasıl olmasına ilişkin yaptıkları çalışmada } \\
\text { inovasyon kültürünü üç bileşen halinde tanımlamışlardır. } \\
\text { Bunlar: 1. inovasyonu destekleyen kuruluş çapında paylaşılan } \\
\text { temel değerler 2. inovasyon için kuruluş çapında normlar } 3 . \\
\text { algılanabilir inovasyon odaklı uygulamalar. }\end{array}$ \\
\hline Brettel \& Cleven & 2011 & $\begin{array}{l}\text { Organizasyonların sürekli bir şekilde öğrenen bir yapı ile pazarın } \\
\text { talepleri ve pazarın şu anda sundukları arasındaki farkları tespit } \\
\text { ederek kendilerini geliştirme eğiliminin derecesi olarak } \\
\text { tanımlanmaktadır. }\end{array}$ \\
\hline Liu \& Fellows & 2012 & $\begin{array}{l}\text { Organizasyon için değer ve tutum yaratan bunu geliştiren, kuran } \\
\text { bir düşünce ve davranış biçimi olarak tanımlanmaktadır. }\end{array}$ \\
\hline $\begin{array}{l}\text { Castro, Delgado-Verde, Navas- } \\
\text { Lopez \& Cruz-Gonzalez }\end{array}$ & 2013 & $\begin{array}{l}\text { Çalışanların ürün inovasyon sürecini kolaylaştırabilecek ortak } \\
\text { değerlerini, inançlarını ve varsayımlarını ifade eden değer olarak } \\
\text { tanımlamaktadır. }\end{array}$ \\
\hline Hofstede & 2013 & $\begin{array}{l}\text { İnovasyon, teknoloji, bilgi alışverişi, girişimcilik faaliyetleri ve } \\
\text { belirsizliğe karşı tutumun bir göstergesi olarak tanımlamıştır. }\end{array}$ \\
\hline R. Bader, Vanbrabant \& Enkel & 2014 & $\begin{array}{l}\text { Pazar yönelimini ve örgütsel öğrenmeyi teşvik eden, yeni } \\
\text { çözümleri, teknolojiyi ve pazarları destekleyen, risk alabilen ve } \\
\text { başarısızlığı tolere eden sağlam bir ortam olarak } \\
\text { tanımlamaktadır }\end{array}$ \\
\hline Unger, Rank \& Gemünden & 2015 & Kurum kültürünün bir alt kümesi olarak tanımlanmaktadır. \\
\hline
\end{tabular}




\begin{tabular}{|c|c|c|}
\hline Keles \& Battal & 2017 & $\begin{array}{l}\text { Dinamik ve akıllı bir kültür şeklinde tanımlayarak bu kültürde } \\
\text { bulunması geren parametreleri insan ve yönetim sistemlerinden } \\
\text { oluştuğunu vurgulamaktadır. Keles ve Battal; dinamik ve akıllı } \\
\text { bir kültürü IVALUE7 adını verdikleri bir şekil oluşturarak } \\
\text { bunlardan herhangi biri olmadan değerli bir kültür } \\
\text { oluşmayacağını savunmaktadır. Bu yedi sütunda ise; insan } \\
\text { yönetimi, fikir tasarımı ve teknoloji yönetimi, altyapı yönetimi, } \\
\text { finans ve fon yönetimi, yenilikçi strateji yönetimi, fikir } \\
\text { mülkiyeti ve iş birliği yönetimi parametreleri yer almaktadır. }\end{array}$ \\
\hline Chouteau, Forest \& Ngueyen & 2018 & $\begin{array}{l}\text { Yenilik aşamasında kültür oluşumunun sadece teknik bir kültür } \\
\text { ile değil de girişimcilik kültürü ile de ilişkisinin olduğu bir süreç } \\
\text { olarak tanımlanmaktadır. }\end{array}$ \\
\hline Davies \& Buisine & 2018 & $\begin{array}{l}\text { Organizasyonun genelinde yenilikçi düşünmeyi doğal kılan ve } \\
\text { bütün çalışanları inovasyon faaliyetlerine teşvik eden özel bir } \\
\text { yapılanma olarak tanımlanmaktadır. }\end{array}$ \\
\hline Iş1k & 2018 & $\begin{array}{l}\text { Örgütün bütün çalışanlarının yenilik yapmayı benimsediği ve } \\
\text { uygulama süreçlerine katıldığı çok yönlü ve karşılıklı bir süreç } \\
\text { olarak tanımlanmaktadır. }\end{array}$ \\
\hline Engel & 2018 & $\begin{array}{l}\text { Liderlerin yaratıcı düşünce ve davranışları beslemek için } \\
\text { yetiştirdikleri kültür olarak tanımlamaktadır. }\end{array}$ \\
\hline Didier & 2018 & $\begin{array}{l}\text { Kişiyi endüstriyel ve endüstriyel sonrası kültürlere geri } \\
\text { döndüreceğini ve bu da kişiyi eskiye iten inatçı bir yenilik } \\
\text { arayışına götüreceğini söylemektedir. Bu yenilik arayışının ise; } \\
\text { radikal (eski) yenilik ve daha yeni olan artırımlı yenilik gibi iki } \\
\text { karakteristik biçim aldığını ortaya koymaktadır. }\end{array}$ \\
\hline Jin, Navare \& Lynch & 2019 & $\begin{array}{l}\text { İnovasyona açık bir ortam, değişime ve geleceğe yönelik piyasa } \\
\text { şekillendirebilen bir zihniyet, risk almaya ve sürekli öğrenmeye } \\
\text { istekli olan bir dizi ortak inanç ve davranış biçimleri olarak } \\
\text { tanımlamaktadır. }\end{array}$ \\
\hline
\end{tabular}

İnovasyon kültürü, yenilikçi düşünme, gelişim ve yenilikçiliğe yönelik algılanan uygulamaları desteklemektir. İnovasyon kültürü durağan değildir ve zamanla değişim içerisindedir. Bu yüzden yaratıcılık, öğrenme, düşünme ve iletişim gibi değerler teşvik edilerek inovasyona dayalı kültürlerden 
inovasyona yardımcı bir kültürün oluşturulması gerekliliğinden bahsedilmektedir (Liu \& Fellows, 2012, s. 77). İnovasyon kültürü oluşturulduğunda her zaman olumlu bir etki yaratmayabilir. Hatta iyi bir kültürün sonucunda başarısızlıklar bile oluşabilir. Ama bu başarısızlıktan bile bir kazanım çıkarmak inovasyonun temel yapısının gereğidir. Böyle durumlarda inovasyon kültürünü geliştirmenin beş stratejisi olduğu savunulmaktadır (Liu \& Fellows, 2012, s. 78). Bu stratejiler;

1. Yazılı olmayan kuralların inovasyon ile nasıl bir ilişki içerisinde olduğunu anlamak ve bunu tanımlayabilmek.

2. $\quad$ Örgütün riskle karş1 karşıya geldiği durumda bile geri dönüşü yüksek projelerin sürdürebilirliğini sağlamak ve risklerden kaçınmayı öğrenerek kısa vadeli yaklaşımları ele alabilmek.

3. Fırsattan doğan riskleri tanımak ve bazen riskli projeleri yürütmek için kaynakları kullanmayı bilmek.

4. Kurumun paydaşları arasında açık inovasyon birlikleri kurmak.

5. Yönetim alanındaki davranışların inovasyon ile olan ilişkisinin, kamudaki açık belgelerle uyumlu olduğundan emin olmak.

İnovasyon kültürünün gelişimi sağlandıktan sonra bu kültürün belirli özelliklere sahip olması gerekmektedir. Yiğit (2014) yaptığı sistematik literatür analizinde inovasyon kültürü özelliklerini şu bileşenler altında toplayarak özetlemiştir: 1. örgüt kültünün adhokrasi kültür tipi özelliği 2. örgütsel öğrenmenin gerçekleşmesi 3. katılımcı karar verme sürecinin sağlanması 4. yöneticilerin açık görüşlü olmas1 5. liderin vizyonunu rahatça ifade edebilmesi 6. risk alabilmenin ve belirsizliği kabul etmenin teşvik edilmesi 7. rekabetçi, performans odaklı bir kültürün oluşturulması 8 . grup ve takım çalışmasına önem verilmesi 9. müş̧eri odaklılık 10. başarısızlıktan ders alma 11. değişim yaratma 12. stratejik yönelimi inovasyon odaklı gerçekleştirmek, işletme amaçları, hedefleri, misyonu ve vizyonunun inovasyon odaklı olması 13. ödüllendirme 14. çalışanlara bireysel destek sağlanması 15. çalışanların bireysellik ve bağımsızlıklarının desteklenmesi 16. hem iç hem de dış iletişime önem verilmesi 17. örgütsel güvene önem verilmesi

\section{İnovasyon Kültürünün Alt Boyutları}

Anlamsal zorluklara rağmen, kültür, örgüt ve inovasyon arasında güçlü bağ hakkında şüphe yoktur. Çeşitli yazarlar, farklı bakış açıları ve deneysel çalışmalar, organizasyon, kültür ve inovasyon arasındaki bu güçlü bağlantıyı desteklemektedir. İnovasyon kültürü modelleri ise bu üçlü arasındaki bağı açıklamak için uygun bir teorik metodolojidir (Morente, Ferràs, \& Zizlavsky, 2018). Morente, Ferràs ve Zizlavsky (2018) inovasyon kültürü modelleri üzerine yapmış oldukları çalışmada Tablo 2'de görüldüğü üzere inovasyon kültürü ile bağlantılı 7 temel örgüt kültürü modeline ulaşmışlardır.

Hofstede (1984) tarafından yapılan sınıflandırma kurum içi uygulamalardaki değişikliklerin kültürel değişimleri tetiklediği ve bu durumun da zaman içerisinde çeşitli sosyal grupların oluşması temeline dayanmaktadır. Hofstede'in aksine Schein (2004), modern organizasyonun kültürle ilgili temel sorunlarını kültürün kendini gösterdiği farklı seviyeler arasındaki ayrım eksikliğinden kaynaklandığını belirterek kültürün alt kırılımlarını tek bir seviyede incelememiştir. Görünürden görünür olmayan bir yapıya doğru örgüt yapısı ve süreçlerden, değerlere ve son olarak da varsayımlara doğru üç katmanda kültürün boyutlarını incelemiştir. Cameron ve Quinn (2006) kültürel boyutları içe/dışa yönüklük, esneklik-durağanlık, değişimin hızı ve derecesine göre dörtlü bir matris harita yapısında inceleyerek bu matrise karşılık gelen dört rekabet değeri tanımlamışlardır (Morente, Ferràs ve Zizlavsky 2018, s. 3-5). 
Tablo 2. Inovasyon Kültürü ile Bağlantılı Örgüt Kültürü Modelleri

\begin{tabular}{|c|c|c|}
\hline Yazar & Çalışma & Boyutlar \\
\hline $\begin{array}{l}\text { Hofstede } \\
\text { (1984) }\end{array}$ & $\begin{array}{l}\text { Hofstede'nin Kültürel } \\
\text { Boyut Modeli }\end{array}$ & $\begin{array}{l}\text { Güç mesafesi, belirsizlik, bireycilik, feminenlik/maskülenlik, } \\
\text { zaman, kısıtlama ve hoşgörü }\end{array}$ \\
\hline Schein (2004) & $\begin{array}{l}\text { Schein'in Çok Katmanl1 } \\
\text { Örgüt Kültürü Modeli }\end{array}$ & $\begin{array}{l}\text { Örgüt yapısı ve organizasyonel süreç, değerler (stratejiler, } \\
\text { amaçlar, görüşler, gerekçeler), varsayımlar (algılar, inançlar, } \\
\text { düşünceler, duygular.) }\end{array}$ \\
\hline $\begin{array}{l}\text { Cameron \& } \\
\text { Quinn (2006) }\end{array}$ & $\begin{array}{l}\text { Cameron ve Quinn'nin } \\
\text { Rekabetçi Değerler } \\
\text { Modeli }\end{array}$ & $\begin{array}{l}\text { Kültürel boyutlar (iç-dış odak, esneklik-durağanlık, değişim } \\
\text { hızı, değişim derecesi), Rekabet değerleri (hiyerarşi, klan, } \\
\text { pazar, adhokrasi) }\end{array}$ \\
\hline $\begin{array}{l}\text { Harrison \& } \\
\text { Stokes (1992) }\end{array}$ & $\begin{array}{l}\text { Harrison ve Stokes'in } \\
\text { Modeli }\end{array}$ & Rol, başarı, güç ve destek \\
\hline $\begin{array}{l}\text { Deal \& } \\
\text { Kennedy } \\
(1982)\end{array}$ & $\begin{array}{l}\text { Deal \& Kennedy’in } \\
\text { Modeli }\end{array}$ & $\begin{array}{l}\text { Çok çalış sert oyna kültür, sert adam/maço kültürü, süreç } \\
\text { kültürü ve şirket bahis kültürü }\end{array}$ \\
\hline $\begin{array}{l}\text { Denison } \\
(2001)\end{array}$ & $\begin{array}{l}\text { Denison’ın Örgüt } \\
\text { Kültürü Araştırması }\end{array}$ & $\begin{array}{l}\text { Dört özellik (adapte olabilirlik, misyon, tutarlılık ve ilgi) ve } \\
\text { iki eksen (dikey, yatay) }\end{array}$ \\
\hline $\begin{array}{l}\text { Hatch \& } \\
\text { Schultz (2009) }\end{array}$ & $\begin{array}{l}\text { Hatch ve Schultz’un } \\
\text { Örgütsel Kimlik } \\
\text { Dinamikleri Modeli }\end{array}$ & Kültür, kimlik ve görüntü \\
\hline
\end{tabular}

Kaynak: Morente, Ferràs, \& Zizlavsky, 2018

Denison (2001) örgüt kültürünün iki temel işlevini organizasyonu bir arada tutmak ve dönüşüm hareketinin temel bir parçası olarak görmüş ve buna göre bir sınıflandırmaya gitmiştir. Harrison ve Stokes (1992)'un modeli büyük ölçüde örgütsel birimler arasındaki sosyal etkileşime, onun değerlerine ve motivasyonuna ve yapısal gücün nasıl kullanıldığına bağlı olan dört tür örgütsel kültürünü birbirinden ayırır. Deal \& Kennedy (1982) geri bildirim hızı ve risk derecesine göre iki eksende altı boyut tanımlamışlardır. $\mathrm{Bu}$ altı boyuta göre de tabloda belirtildiği üzere 4 temel kültür boyutu tanımlamışlardır. Hatch \& Schultz (2009) Örgütsel Kimlik Dinamikleri Modeli'ni ortaya koymuşlardır. Modele göre 'kimlik', bir yandan dış çevre ve paydaşlarla ilişki (Görüntü), diğer yandan iç organizasyon yapısı (Kültür) arasındaki istikrarsız ve dinamik dengeden oluşur. Modele göre kimlik, kültürü ifade eder ve kimlik başkalarının imgelerini (görüntülerini) yansıtır (Morente, Ferràs ve Zizlavsky 2018, s. 3$5)$.

Yazarların farklı zamanlarda yapmış oldukları modellemelerde görüldüğü üzere çalışmanın ana odağı inovasyon kültürü modelleri olmasına rağmen kapsam, kültür ve örgüt kültürü boyutları ile sınırlı kalarak inovasyon kültürü boyutlarına yeterince inilememiştir. Doğrudan inovasyon kültürü üzerine yapılan çalışmalar ise oldukça azdır. Bu çalışmaları Tablo 3’te özetlemek mümkündür. 
Tablo 3. Inovasyon Kültürüne İlişkin Ortaya Konmuş Modeller

\begin{tabular}{|c|c|}
\hline Yazar & İnovasyon Kültürü Boyutları \\
\hline $\begin{array}{c}\text { Villaluz \& } \\
\text { Hechanova } \\
(2019)\end{array}$ & $\begin{array}{c}\text { Rol modellik ve liderlik, iletişim stratejileri, çalışanların } \\
\text { katılımı ve iklim, destekleyici sistemler ve yapı, eğitim } \\
\text { ve geliştirme, değerlendirme ve ödül }\end{array}$ \\
\hline $\begin{array}{c}\text { Rao \& } \\
\text { Weintraub } \\
(2013)\end{array}$ & $\begin{array}{c}\text { Değerler, davranışlar, iklim, kaynaklar, süreçler ve } \\
\text { başarı }\end{array}$ \\
\hline Dobni (2008) & $\begin{array}{c}\text { Uygulama, çalışan katılımı, organizasyonel öğrenme, } \\
\text { pazar konumlandırma, stratejik tutum, değer, yaratıcılık } \\
\text { ve yetki }\end{array}$ \\
\hline
\end{tabular}

Bu modellerden en günceli Villaluz \& Hechanova (2019) tarafından sunulan çalışma olmuştur. $\mathrm{Bu}$ çalışmada inovasyon kültürünü etkileyen bileşenlerin rol modellik ve liderlik, iletişim stratejileri, çalışanların katılımı ve iklim, destekleyici sistemler ve yapı, eğitim ve geliştirme, değerlendirme ve ödül olarak sıralanmıştır.

Rol modellik ve liderlik, liderlerin yenilikçi olduğu ve başkalarını da yenilikçi olmaya teşvik ettikleri algısını yansıtmaktadır. Iletişsim stratejileri, yaratıcıllı̆ın ve inovasyonun işletme stratejileri, vizyonu ve misyonunun bir parçası olarak değerlendirilip değerlendirilmediğini ölçmektedir. Çalışanların katılımı ve iklim, çalışanların birlikte çalıştığı ve çalışanların işlerinde fazladan yol kat edebildikleri bir ortamı göstermektedir. Destekleyici sistemler ve yapı, inovasyonu güçlendiren örgüt politikaları, süreçleri ve fiziksel çevre ile ilgilidir. Ĕgitim ve geliştirme, organizasyonda inovasyonu destekleyen öğrenme faaliyetleri ve yeni girişimlere sahip olmakla ilgilidir. Değerlendirme ve ödül, kaynakların ve teşviklerin sağlanması yoluyla organizasyonda inovasyonun nasıl desteklendiğini göstermektedir (Villaluz \& Hechanova, 2019).

Dobni (2008) yaptığı inovasyon kültürünün ölçümlenmesi çalışmasında inovasyon kültürünü dört boyutta incelemiştir. Bunlar: 1. İnovasyona olan niyet 2. İnovasyon altyapısı 3. Pazar yönlendirmesi 4. Uygulama. Bu dört boyuta ilişkin gerçekleştirmiş olduğu çalışmada bu boyutları 7 alt ölçek altında inceleyerek inovasyon kültürünü ölçümlemiştir. Bunlar: 1. Uygulama boyutu 2. Çalışan katılım boyutu 3. Organizasyonel öğrenme boyutu 4. Pazar konumlandırma boyutu 5. Stratejik tutum boyutu 6. Değer boyutu 7. Çalışanların yaratıcılık ve yetki boyutu.

Uygulama boyutu, yenilikçi fikirler için geniş inovasyon kaynaklarının varlığı ve bu varlıkları kullanarak yenilikçi fikirlerin ticarileşebilmesini öngören inovasyon sürecini ifade etmektedir. Çalışanların katılımı, çalışanların kendilerini rahat ifade edebildikleri iletişim ve iş birliğine açık bir ortamı ifade eder. Organizasyonel ögrenme, inovasyon faaliyetleri için gerekli eğitim ve mentorluk programlarının varlığını ortaya koymaktadır. Pazar konumlandırma, pazar ve rekabet yapısının bilindiği ve buna göre inovasyonun planlaması ve stratejilerin belirlenmesini ifade etmektedir. Stratejik tutum, inovasyon stratejilerinin belirli plan, vizyon, misyon ve hedefler çerçevesinde yürütülmesini söylemektedir. Değer, müşteriler için neyin değer yarattığı konusunda fikir birliği olması, değeri yakalama ve uygulama konusunda birlikte hareket edilmesi, bunun için gerekli süreç ve prosedürlerin çıkarılmasını söylemektedir. Çalışanların yaratıcılık ve yetki boyutu ise çalışanların kendini yaratıcı hissetmesi ve bunun için gerekli ortamın sunulmasını ortaya koymaktadır (Dobni, 2008). 
Rao \& Weintraub (2013) "Innovation Quotient" ismini verdikleri çalışmalarında inovasyon kültürünü ölçümlenmeye yönelik bir çalışma oluşturmuşlardır. Bu çalışma için 6 bloktan oluşan bir yapı tanımışlardır. Bunlar Şekil 1'de de görüleceği üzere değerler, davranışlar, iklim, kaynaklar, süreçler ve başarıdan oluşmaktadır.

Değerler, girişimciliği, yaratıcılığı destekleyen ve öğrenmeye açık bir ortamı ifade eder. Davranışlar, özellikle liderlerin inovasyon faaliyetlerinde nasıl bir enerji sağladıkları, bu faaliyetlere ne ölçüde katılım sağladıkları ve bu konularda işletme için ne gibi olanaklar sundukları ile ilgilenmektedir. Iklim, inovasyon faaliyetlerinde iş birliği, güven, açıklık ve sadeliği ifade eder. Kaynaklar, inovasyon projelerine ayrılan işgücü, inovasyon faaliyetleri için kurulan sistem ve yeni firsatlar için üzerinde durulan projeleri kapsar. Süreçler, yenilikçi fikirlerin seçilmesinden ticarileşebilmesine kadar olan inovasyon sürecini ifade eder. Başarı ise inovasyon faaliyetlerinin başarısının iç ve dış çevrede nasıl algılandığının bir göstergesidir (Rao \& Weintraub, 2013).

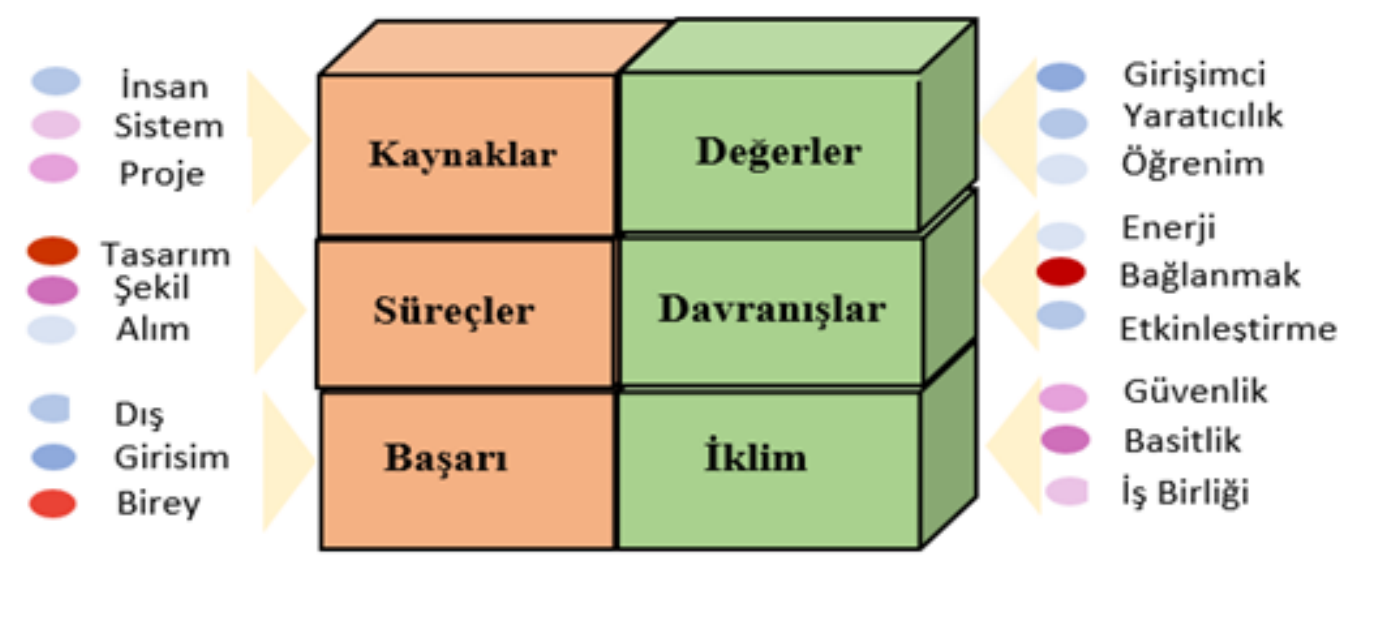

Şekil 1. Rao ve Weintraub'un İnovasyon Kültürüne Illişkin Blok Modeli

\section{İnovasyon Kültürü Modellerinin Analizi ve Değerlendirme}

Morente, Ferràs ve Zizlavsky (2018) tarafindan inovasyon kültürü modelleri üzerine yapılan sınıflandırma çalışmasında farklı modellere ulaşıldıysa da bu modeller örgüt kültürünün boyutlarını irdelemenin ötesine geçememiştir. Yazarlar tarafından sunulan çalışmada da bu durum belirtilmektedir. Dobni (2008), Rao \& Weintraub (2013) ve Villaluz \& Hechanova (2019) tarafindan farklı zamanlarda yapılan çalışmaların analizlerinde inovasyon kültürü bileşenlerinin hemen hemen birbirine yakın boyutlardan oluştuğu gözlemlenmiştir. Dobni (2008) ve Villaluz \& Hechanova (2019) tarafından ortaya konulan model, inovasyon çıktılarını da ölçmek için gerekli performans göstergelerini içerirken Rao \& Weintraub (2013) tarafından ortaya konan model kültürel örgüt değerlerine daha çok odaklamış durumdadır. Burada ortaya çıkan temel sonuç bazı inovasyon kültürü ölçümlemelerinde inovasyon performans göstergelerine odaklanılmış olmasıdır. Oysaki inovasyon ve inovasyon kültürü ölçümlemesi birbirinden bağımsız olarak değerlendirilmelidir. Biri yenilikçilik göstergelerini ortaya koyarken bir diğeri bu yenilikçilik göstergelerine ulaşabilmek için sahip olunması gereken anlayış, değer ve normları kapsaması beklenmektedir. Bu yüzden Rao \& Weintraub (2013) tarafından geliştirilen modelin 
inovasyon kültürü yapısına ve bir kurumda inovasyon kültürünü ölçümlemede daha uygun bir model olduğu söylenebilir.

İnovasyon karnesi veya inovasyon performansının ölçümlenmesine ilişkin yapılan çalışmalar daha geniş bir perspektiften ele alınabilir; ama inovasyon kültürünün ölçümlenmesi, daha spesifik ve kendine özgü bileşenler ihtiva etmesi gerekmektedir. Diğer taraftan inovasyon kültürü, inovasyon yönetiminin ve inovasyon başarısının en önemli bileşenlerinden birisini oluşturmaktadır (Cormican \& O'Sullivan, 2004; Eveleens, 2010; Hartman, 2006; Olmos-Peñuela, 2017; Xu vd., 2007). Yalnız inovasyon kültürünün kendine özgü bileşen ve boyutlar altında ölçümlenmesi gerekmektedir. Bu yüzden bu çalışma kapsamında incelenen yapılar içerisinde Rao \& Weintraub (2013) tarafından sunulan modelin, kültür, örgüt kültürü ve inovasyon bağlamında daha uygun bir model olduğu söylenebilir. Ayrica Rao \& Weintraub (2013) tarafindan ortaya konulan modelin, Hofstede (1984) ve Schein (2004) gibi yazarlar tarafından ortaya konulan ve daha çok kültür ve örgüt kültürü ile ilgili model yapılarına da daha uygun olduğu ve bu model yapılarına ek olarak yenilikçi bir anlayış ile inovasyon kültürünü de beslediği ifade edilebilir. Diğer bir ifade ile bu model, Morente, Ferràs ve Zizlavsky (2018) tarafından sunulan ve farklı zamanlarda farklı yazarlar tarafindan ortaya konan inovasyon kültürü modellerinin eksik kaldığı ve daha çok örgüt kültürü boyutlarını inceledikleri çalışmaların eksikliğini kapatarak inovasyon kültürünün temel boyutlarına daha çok eğilmiştir.

Rao \& Weintraub (2013) ortaya koyduğu modelde yenilikçi kültürü altı bina bloklarına benzeterek her bir boyutu ortaya koymuşlar ve bu boyutları da etkileyen alt boyutları belirlemişlerdir. $\mathrm{Bu}$ boyutlar yukarıda da belirtildiği üzere kaynaklar, süreçler, başarı, değerler, davranışlar ve iklimdir. Modelde altı yapı taşından her biri ise üç faktörden oluşmaktadır. Kaynaklar; insan, sistem ve proje olarak, süreçler; tasarım, şekil ve alım, başarı; dış faktör, girişim ve birey, değerler; girişimci, yaratıcılık ve öğrenim, davranışlar; enerji, bağlanmak ve etkinleştirme ve iklim; güvenlik, basitlik ve iş birliği olarak karşımıza çıkmaktadır. Bu modelin temelinde iki soru yer almaktadır. Birincisi; yenilikçi bir kurum kültürü nedir? İkincisi; yenilikçi bir kurum kültürünüz yoksa bunu inşa etmenin herhangi bir yolu var mı? Rao \& Weintraub (2013) yenilikçi bir kültürün temel unsurlarını oluşturmada bu modeli ele alarak iki soruyu da değerlendirme aracı olarak ele almışlardır.

Yenilikçi bir kültür bu altı yapı taşının temelini oluşturmaktadır. Bu yapı taşları ise birbirine bağlıdır. Örneğin; inovasyonu teşvik etmek için kaynaklar, süreçler ve başarı etkili olurken; değerler, davranışlar ve iklim başarının nasıl tanımlandığı ve ölçüldügü üzerine bir etkiye sahip olduğu savunulmuştur. Kaynaklar, süreçler ve başarı ölçümlenmesi daha kolay iken diğer yapı taşlarının ölçümlenmesi daha zor olduğu söylenmektedir. Bunun nedeni ise insan odaklı değerlerin olmasından kaynaklanmaktadır. Ayrıca bu yapı taşlarının etkilerinin soyut unsurlardan somut unsurlara doğru hareket etmesi ile yenilikçi kültürün daha ölçülebilir ve yönetilebilir hale geldiği savunulmaktadır.

İnovasyon kültürünü doğru bir şekilde ölçümleyebilmek için, bir çalışma ortamındaki üst düzey yöneticilerin, yaratıc1lı̆̆ ön planda tutarak inovasyon sürecindeki her bir parçayı bir bütün olarak ölçümlendirmesi ve bu ölçümün yapıldığı oluşumdaki inovasyon kültürünün ne kadar iyi yönetildiğinin çıktısını bizlere sunabilmesi en önemli etkendir. Rao \& Weintraub (2013) da ortaya koymuş oldukları 'Innovation Quetient' çalışmasında tam da bu unsurların önemine odaklanarak, inovasyon kültürünün ölçümlenmesinde yapılacak olan faaliyetlere rehberlik edebilecek nitelikte bir yapının oluşturulmasına gayret gösterilmiştir.

\section{SONUÇ VE DEĞERLENDİRME}

İnovasyon kültürü, inovasyon başarısını ve inovasyon yönetimini etkileyen temel bir yapı taşıdır. Toplum ile örgüt kültürü, inovasyon çalışmalarını etkileyerek birçok farklı unsuru ortaya çıkarmış ve 
inovasyon kültürü kavramının çok yönlü ele alınmasına olanak sağlamıştır. Bu yüzden bir toplumda değişen kültürel farklılıklar, inovasyon kültürü çalışmalarını tüm yönüyle etkiyebilmektedir.

Son zamanlarda inovasyon yönetimi içerisinde önemli bir başarı faktörü kurumların belirli performans kriterleri sunarak kurum içi ve dışı birçok bilgi ve teknolojiye ulaşıyor olmasıdır. Böyle bir ortamın oluşması ve giderek daha aktif hale gelmesi için örgüt içerisinde inovasyon odaklı kültürün oluşması gerekmektedir. İnovasyon kültürünü oluşturacak ortamların en iyi şekilde ayarlanması, her kurum için gelişmeyi kaçınılmaz kılar. İnovasyon odaklı kültüre sahip bir örgütte ödüllendirme sistemi, hoşgörü, iyi bir iletişim sistemi, fikir alışverişi gibi birçok interaktif davranış etkin bir şekilde işler. Hiyerarşik ve bürokratik bir yapının olduğu bir örgütte yenilikler ve farklılıklar olmayacaktır.

İnovasyon kültürü kavramı literatürde her araştırmacı için farklı noktalar ile ele alınmış ve incelenmiştir. Bazı araştırmacılar sadece yenilik yönüyle ele alırken, bazıları kültür ve örgüt kültürü kavramı ile ilişkilendirmiştir. Yapılan araştırmalara bakıldığında inovasyon kültürünün olmadığı bir örgütün günümüz rekabet şartlarında varlığını sürdürebilmesi zor gözükmektedir. İşte bu çalışmada önerilen model çok yönlü bir yapıyı içinde barındırdığı için temel referans olarak ele alınmıştır. Çalışmaların birçoğuna bakıldığında ya tek yönlü kültür öğeleri ele alınmış ya o dönemin etkilediği yapı taşları ele alınarak belirli unsurlar şeklinde ortaya konulmuş ya da inovasyon kültürü, inovasyon performansı gösterge bileşenleri ile ölçümlenmeye çalışılmıştır. Rao ve Weintraub (2013) sunduğu modelde örgütün yenilikçilik ekseninde içinde barındırması gereken bütün özellikler ortaya konarak inovasyon kültürünün birçok bileşenini gün yüzüne çıkarmıştır.

$\mathrm{Bu}$ çalışma inovasyon kültürü ve inovasyon kültürünün boyutları üzerine yapılan çalışmaların azlığı göz önüne alındığında literatüre önemli bir kazanım getirmektedir. Kavramsal çerçeve ve ortaya konan modeller analiz edilerek kurumlarda inovasyon kültürünün doğru ve etkin bir şekilde ölçümlenmesi için ortaya konulan modeller içerisinde uygun olanları değerlendirilmeye çalışılmıştır. İlerleyen çalışmalarda Rao ve Weintraub (2013)'un "Innovation Quetient”" çalışması Türkiye'ye uyarlanarak Türkiye'deki işletmelerin inovasyon kültürü karnesi ortaya çıkarılmaya çalışılacaktır. Bunun için öncelikli olarak "Innovation Quetient” çalışmasının Türkiye'de pilot çalışması ve geçerliliği yapılarak bu çalışmanın Türkiye'de faaliyet gösteren kurumların inovasyon kültürünü ölçümlemede ne kadar etkin sonuçlar ortaya koyduğu analiz edilecektir. Ortaya çıkan sonuçlara göre yeni bir inovasyon kültürü ölçeği geliştirme çalışmaları da gerçekleştirilebilecektir. 


\section{KAYNAKÇA}

Abdul-Halim, H., Ahmad, N. H., Geare, A., \& Thurasamy, R. (2018). Innovation Culture in SMEs: The Importance of Organizational Culture, Organizational Learning and market Orientation, Entrepreneurship Research Journal, 9(3), 1-14.

Bader, K., Vanbrabant, L., \& Enkel, E. (2014). Drivers of Firm Openness: Innovation culture and Strategic Direction as Stimulating Factors, Annual Meet. Eur. Acad. Manag, Valencia, Spain.

Bakovic, T., Lazibat, T., \& Sutic, I. (2013). Radical İnnovation Culture in Croatian Manufacturing İndustry. Journal of Enterprising Communities: People and Places in the Global Economy, 74-80.

Best, J. (2018). Part V Culture. Breaking Dijital Gridlock: İmprowing Your Bank's Dijital Future by Making Technology Changes Now, First Edition, 177-194.

Boyac1, M. (2018). Ege Üniversitesi Ziraat Fakültesi’nde İnovasyon Süreci ve Kültürü. Ege Üniversitesi Ziraat Fakültesi Dergisi, 479-490.

Boyacı, M. (2019). Kamu Tarımsal Araştırma Kuruluşlarında İnovasyon Süreci ve Kültürü: Ege Bölgesi Örneği. Ege Üniversitesi Ziraat Fakültesi Dergisi, 281-295.

Brettel, M., \& Cleven, N. J. (2011). Innovation Culture, Collaboration with External Partners and NPD Performance, Creativity and Innovation Management, 20(4), 253-272.

Burdon, S., Kang, K., \& Mooney, G. (2016). Understanding the Key Attributes for a Successful Innovation Culture. International Journal of Enterprise Information Systems (IJEIS), 12(4), 70-82.

Büschgens, T., Bausch, A., \& Balkin, D. B. (2013;30(4)). Organizational Culture and Innovation:A Meta-Analytic Review. J PROD INNOV MANAG, 1-19.

Cormican, K., \& O'Sullivan, D. (2004). Auditing Best Practice for Effective Product Innovation Management, Technovation, 24(10), 819-829.

Çalışır, T. S. (2019). İnovasyon, Teknoparkların Teknoloji Geliştirmede ki Önemi ve Türkiye Örneği. https://tez.yok.gov.tr/UlusalTezMerkezi/tezSorguSonucYeni.jsp

Danks, S., Rao, J., \& Allen, J. M. (2017). Measuring Culture of innovation: A Validation Study of the Innovation Quotient Instrument (part one), Performance Improvement Quarterly, 29(4), 427-454.

Danks, S., Rao, J., \& Allen, J. M. (2017b). Measuring Culture of Innovation: A Validation Study of the Innovation Quotient Instrument (part two). Performance Improvement Quarterly, 30(1), 29-53.

Davies, M. (2018). Innovation Culture in Organizations. Science, Technology and Innovation Culture, 103-114.

Didier, J. (2018). Technical Culture and Innovation Culture: Reconciling through Design. Science, Technology and Innovation Culture.

Dobni, C. B. (2008). Measuring Innovation Culture in Organizations: The Development of a Generalized Innovation Culture Construct Using Exploratory Factor Analysis, European Journal of Innovation Management, 11(4), 539-559.

Engel, A. (2018). Part IV Promoting Innovation Culture. Pracctial Creativity and Innavation in Systems Engineering, First Edition, 205-325.

Hartmann, A. (2006). The Context of Innovation Management in Construction Firms. Construction Management and Economics, 24(6), 567-578.

Herzog, P., \& Leker, J. (2010). Open and Closed Innovation-Different Innovation Cultures for Different Strategies, International Journal of Technology Management, 52(3/4), 322-343.

Hofstede, G. (1984). Culture's Consequences-International Differences in Work-Related Values. London : Sage Publications.

Hofstede, G. (2003). Culture's Consequences: Comparing Values, Behaviors, Institutions, and Organizations Across Nations. Thousand Oaks, CA: Sage.

Hsieh, Y. J., Wu, Y. J. (2019). Entrepreneurship Through the Platform Strategy in the Digital Era: Insights and Research Opportunities, Computers in Human Behavior, 95, 315-323. 
Ismail, W. K., \& Abdmajid, R. (2007). Framework of The Culture of İnnovation: A Revisit. Jurnal Kemanusiaan, $39-49$.

Işık, M. (2018). İnovasyon Kültürünün Hizmet İnovasyonu Performansına Etkisi: Bitlis İli Hizmet Sektöründe Bir Araştırma. Atatürk Üniversitesi İktisadi ve İdari Bilimler Dergisi, 351-366.

Jin, Z., Navare, J., \& Lynch, R. (2019). The Relationship Between Innovation Culture and Innovation Outcomes: Exploring the Effects of Sustainability Orientation and Firm Size, R\&D Management, 49(4), 607-623.

Keleş, Ö., \& Battal, T. (2017). A Model For Innovation Culture Management In Organizations (IVALUE 7). International Journal of Innovation, 361-374.

Liu, A., \& Fellows, R. (2012). Culture and Innovation. Construction Innovation and Process Improvement, 64-94.

Martín-de Castro, G., Delgado-Verde, M., Navas-López, J. E., \& Cruz-González, J. (2013). The Moderating Role of Innovation Culture in the Relationship Between Knowledge Assets and Product innovation, Technological Forecasting and Social Change, 80(2), 351-363.

Morente, F., Ferràs, X., \& Zizlavsky, O. (2018). Innovation Cultural Models: Review and Proposal for Next Steps. Revista Universidad y Empresa, 20(34), 53-81.

Olmos-Peñuela, J., García-Granero, A., Castro-Martínez, E., \& D’Este, P. (2017). Strengthening SMEs' Innovation Culture Through Collaborations with Public Research Organizations. Do all Firms Benefit Equally?, European Planning Studies, 25(11), 2001-2020, 1-20.

Özdemir, L., \& Sönmez, R. V. (2018). Örgütsel Kültürün Ürün İnovasyonu Üzerinde Etkisine Yönelik Bir Araştırma. Süleyman Demirel Üniversitesi Vizyoner Dergisi, 14-26.

Pado, G., \& Tezcan, L. (2018). Kültür ve Kültür Boyutlarının İnovasyon Kapasiteleri Üzerine Etkileri. Uluslararası Bilimsel Araştırmalar Dergisi, 275-292.

Rao, J., \& Weintraub, J. R. (2013). How Innovative is your Company's Culture? Mit Sloan Management Review, 54(3), 28-37.

Schein, E. H. (2004). Organizational Culture and Leadership. Amerika Birleşik Devletleri: Jossey-Bass.

Schein, E.H. (1997). Organizational Culture and Leadership, Jossey-Bass, San Francisco.

Tang, G., Park, K., Agarwal, A., \& Liu, F. (2020). Impact of Innovation Culture, Organization Size and

Technological Capability on the Performance of SMEs: The case of China. Sustainability, 12(4), 1355.

Tetik, S., Emekliler, B., \& Emekliler, N. (2019). Dönüștürücü Liderliğin İnovasyon ve İnovasyon Kültürüne Etkisi: Büyük Ölçekli İşletmelere Yönelik Saha Araştırması. Avrasya Uluslararası Araştırma Dergisi, 165195.

Tian, B. M., Deng, P., Zhang, Y., \& Salmador, M. P. (2018). How Does Culture Influence Innovation? A Systematic Literature Review. Management Decision, 1-37.

Unger, B. N., Rank, J., \& Gemünden, H. G. (2015). Corporate innovation Culture and Dimensions of Project Prtfolio Success: The Moderating Role of National Culture. Project Management Journal , 38-57.

Villaluz, V. C., \& Hechanova, M. R. M. (2019). Ownership and Leadership in Building an Innovation Culture, Leadership \& Organization Development Journal, 40(2), 138-150.

When Innovation Culture Hides Technical Culture. (2018). Science, Technology and Innovation Culture, 24-38.

Xu, Q., Chen, J., Xie, Z., Liu, J., Zheng, G., \& Wang, Y. (2007). Total Innovation Management: a Novel Paradigm of Innovation Management in the 21st Century. The Journal of Technology Transfer, 32(1-2), 9-25.

Yılmaz, Z., \& İncekaş, E. (2018). Türkiye'de İnovasyon ve Bölgesel Kalkınma. Kırkkale Üniversitesi Sosyal Bilimler Dergisi, 155-168.

Yiğit, S. (2014). Kültür, Örgüt Kültürü ve İnovasyon İlişkisi Bağlamında 'İnovasyon Kültürü'. KMÜ Sostal ve Ekonomik Araştırmalar Dergisi, 1-7.

Yiğit, S. (2014). Külttür, Örgüt Kültürü ve İnovasyon İlişsisi Bağlamında "İnovasyon Kültürü”, Karamanoğlu Mehmetbey Üniversitesi Sosyal ve Ekonomik Araştırmalar Dergisi, 2014(2), 1-7. 
Zanjirchi, S. M., Jalilian, N., \& Mehrjardi, M. S. (2019, February). Open Innovation: From Technology Exploitation to Creation of Superior Performance. Asia Pacific Journal of Innovation and Entrepreneurship, 326-340. 


\section{EXTENDED ABSTRACT}

Innovation activities affect societies structurally, socially, and environmentally. The emergence of these innovations for the sustainable competition of societies is closely related to the cultural characteristics of that society. Therefore, culture is a historical process that reveals and shapes the values, lifestyles and thoughts of the people living in the society. This process reveals the formation of an organizational culture for institutions to absorb innovation. Organizational culture is one of the most important factors associated with innovation culture. In this study, we first focus on the concepts of culture, organizational culture and innovation culture and the relationship between these concepts. Organizations' capacity and ability to innovate is directly related to these concepts. Then, we examined the models put forward in the literature regarding how innovation culture is measured in organizations. By evaluating the relationship between the models presented and the innovation culture, we predicted which model would be more functional for future studies.

\section{Culture, Organizational Culture, and Innovation Culture}

Culture is a structure that concerns people with their organizational, national, and social aspects (Best, 2018). In other words, culture is a set of values that includes the value structures of people in a particular region, their characteristics, and behaviors they exhibit. While there is no consensus on the definition of organizational culture in the literature, there is a broader consensus on an important aspect of culture, where groups share or hold certain things in common (Schein, 1997). These are generally defined as the values, norms, attitudes, and behavior patterns that constitute the basic entity of an institution or its sub-units (Herzog and Leker, 2010).

Organizational culture is also expressed as the core of innovative activities carried out by the organization. The innovation culture revolves around this culture in which new ideas are formulated, valued, and supported. In this context, the organizational culture can influence the innovation culture and this culture may become more common or rare in some parts of the organizations. Since organizational culture can encourage creativity and originality through innovation culture, they support each other properly (Abdul-Halim et al., 2018).

\section{Sub-Dimensions of Innovation Culture}

Despite the concept challenges, there is no doubt about the strong relation between culture, organization, and innovation. Various research, and different perspectives support this relation between organization, culture, and innovation. Innovation culture models are a suitable theoretical methodology to explain the link between this triad (Morente, Ferràs, and Zizlavsky, 2018). Although the focus of the most studies on innovation culture models is about culture and innovation, the dimensions of innovation culture could not be explained clearly. Studies in this area mostly measure organizational culture. Studies directly on innovation culture are very few. These are presented as follow.

Villaluz \& Hechanova (2019) listed the components that affect the innovation culture as communicating strategy for innovation, employee engagement and climate, support system and structures, training and development for innovation, evaluation, and rewards. Dobni (2008) examined the innovation culture in four dimensions in the study of measuring innovation culture. These are: 1. Intention to innovation 2. Innovation infrastructure 3. Market orientation 4. Implementation. Rao \& Weintraub (2013) created a framework for measuring innovation culture in their study called "Innovation Quotient". In this study, they defined a structure consisting of 6 blocks. These are: values, behaviors, climate, resources, processes, and success.

\section{Analysis and Evaluation of Innovation Culture Models}

While the models put forward by Dobni (2008) and Villaluz \& Hechanova (2019) include the performance indicators required to measure innovation outputs, the model put forward by Rao \& Weintraub (2013) focuses more on cultural organization values. The main result that emerges is that some innovation culture measurements are focused on innovation performance indicators. However, innovation and innovation culture should be evaluated independently. While one of them reveals the innovation indicators, the other is expected to cover the understanding, values and norms that must be possessed to reach these innovation indicators.

\section{Conclusion}

Innovation culture is a fundamental building block that affects innovation success and innovation management. Society and organizational culture have revealed many different factors by affecting innovation studies and enabled the concept of innovation culture to be addressed in many aspects. Therefore, changing cultural differences in a society can affect innovation culture studies.

The concept of innovation culture has been handled and examined with different views for each researcher. While some deal with it only in terms of innovation, some have associated it with the concept of culture and organizational culture. The model proposed by Rao and Weintraub (2013) has been taken as a basic reference since 
it contains a versatile structure. Considering other studies, either one-sided cultural elements were handled, the building blocks affected by that period were revealed in the form of certain elements or the innovation culture was tried to be measured with innovation performance indicators. As a future study, the "Innovation Quotient" model will be adapted to Turkish firms to analyze the innovation culture of these firms. 